\title{
Health information technology and health care activists: Where is the place of Iranians?
}

\author{
Mobina Ghoochani ${ }^{1}$, Mehdi Kahouei ${ }^{2}$, Morteza Hemmat ${ }^{3}$, Hesamedin Askari Majdabadi ${ }^{4}$, Ali Valinejadi ${ }^{5}$
}

${ }^{1}$ MSc. of Information Technology, School of Allied Medical Sciences, Semnan University of Medical Sciences, Semnan, Iran

${ }^{2}$ Ph.D. of Health Information Management, Associate Professor, Social Determinants of Health Research Center, Semnan University of Medical Sciences, Semnan, Iran

${ }^{3}$ Ph.D. of Health Information Management, Assistant Professor, Social Determinants of Health Research Center, Saveh University of Medical Sciences, Saveh, Iran

${ }^{4} \mathrm{Ph}$.D. of Health Education and Promotion, Assistant Professor, Nursing Care Research Center, Semnan University of Medical Sciences, Semnan, Iran

${ }^{5}$ Ph.D. of Health Information Management, Assistant Professor, Social Determinants of Health Research Center, Department of Health Information Technology, School of Allied Medical Sciences, Semnan University of Medical Sciences, Semnan, Iran

Type of article: Original

\begin{abstract}
Background: The level of knowledge and using health information technology by clinicians, students and staff has always been one of the essential issues in the field of health.

Objective: The objective of the present study was to evaluate HIT knowledge, attitude, and practice habits among health care professionals and students in educational hospitals in Iran.

Methods: This case study was carried out in 2016 on 539 personnel of 65 educational hospitals in Iran entailing three subgroups of physicians $(\mathrm{n}=128)$, medical students $(\mathrm{n}=97)$, and health record staff $(\mathrm{n}=314)$. A pretested selfadministered questionnaire was designed to evaluate the knowledge, attitude and practice of health information technology. It was comprised of three parts of "baseline general characteristics", "knowledge categories", and "attitude and practice".

Results: In total, $28.8 \%$ of participants had a good level of knowledge about computer science, whereas $37.7 \%$ had a poor level of knowledge. A total of $40 \%$ showed good attitude and practice, while $25.6 \%$ had poor attitude and practice. Furthermore, $16.4 \%$ of physicians, $32 \%$ of students and $33.1 \%$ of health record staff had good knowledge, while poor knowledge was reported in $45.3 \%$ of physicians, $25.8 \%$ of students, and $37.6 \%$ of staff $(\mathrm{p}=0.304)$. The trend of good attitude and practice habits were respectively $28.9 \%, 50.5 \%$, and $40.8 \%$ in physicians, students, and staff, whereas these trends were respectively $30.5 \%, 4.1 \%$, and $29.9 \%$ for poor attitude and practice $(\mathrm{p}=0.163)$. Generally, the knowledge level of participants was positively related to the rate of attitude and practice $(\mathrm{r}=0.847, \mathrm{p}<0.001)$, so the higher knowledge level brought about the higher score in attitude and practice.

Conclusion: The level of knowledge and practice of HIT was low among the physicians, students, and staff. Our university can provide a plenary program to promote the level of knowledge and information on practice of HIT.

Keywords: Medical informatics, Health staff, Physicians, Students, Hospitals, Educational
\end{abstract}

\section{Introduction}

Technology is developing rapidly, so it will specifically affect the health domain. In addition to being able to improve health care outputs, information technology (IT) can positively affect the relationship between health care

\section{Corresponding author:}

Assistant Professor Dr. Ali Valinejadi, Department of Health Information Technology, School of Allied Medical Sciences, Semnan University of Medical Sciences, Semnan, Iran.

Tel: +98.2333614664, Fax: +98.2333614664, Email: valinejadi.a@semums.ac.ir

Received: December 28, 2017, Accepted: August 20, 2017, Published: October 2017

iThenticate screening: August 06, 2017, English editing: October 11, 2017, Quality control: October 15, 2017

This article has been reviewed / commented by three experts

(C) 2017 The Authors. This is an open access article under the terms of the Creative Commons Attribution-NonCommercialNoDerivs License, which permits use and distribution in any medium, provided the original work is properly cited, the use is non-commercial and no modifications or adaptations are made. 
professionals and patients $(1,2)$. Health information technology (HIT) means various communication and information technologies that are used to collect, save, transfer and display the patient's data (3). It is also a concept that describes the use of computer systems for accessing health care information by patients, health care providers, insurance companies, and other governmental organizations (4). This technology entails a variety of products and services such as Electronic Health Records (EHR), Tele-health, Mobile Health (m-health), tele-monitoring tools, assistant technologies and sensors. Collecting, sharing and using health information for individuals and health care providers, public health institutions and NGOs would be possible by using all the mentioned technologies $(5,6)$. Health information technology (HIT) embraces a wide range of information and communication technologies that are used to gather, transfer, save, and display the patients' data (3). This notion encompasses a broad diversity of products, technologies, and services such as remote and mobile health technology, cloud-based services, medical devices, tele-monitoring tools, assistant technology, and sensors (7). The potentialities of HIT are as follows: improving the quality, efficiency, outcomes and patient's safety, and reducing the cost of health care (8). By using HIT, health information would be accessible for patients, health care providers, insurance companies, and other governmental agencies. It would also reduce medical errors, costs, and paperwork, while it would increase efficiency, quality of health care, and empowerment of patients and health care professionals (4). To attain these advantages, the acceptance of HIT use is one of the key factors (9). Nevertheless, the acceptance of HIT is very low in most nations (8). More deployment of physicians in HIT makes hospital managers improve the HIT implementation process and increase practice of HIT (10). In Iran, as a developing country, less than half of the students know of the numerous advantages of using IT in research and training and very few of them take advantage of these benefits as educational aids $(11,12)$. In order to motivate students to use IT in all educational and research aspects, it is needed to inform them about various aspects of using it; however, there is not enough information about knowledge and practice patterns of students, and also there are no published or official reports on the knowledge and practice patterns of using IT among health care professionals in Iran. Therefore, the present study aimed to evaluate HIT knowledge and practice among the students and personnel of an educational hospital in Iran. In 2004, Bello carried out a survey on knowledge and practice of IT among health care workers and students in IleIfe (13). Another survey was done by Mohammed et al. on health care professionals in Addis Ababa hospitals, Ethiopia (14). Gour and Srivastava have studied computer knowledge among health care workers of India (15). Another study was done by Srivastava et al. in 2014, on the viewpoint of learners about the role of IT in higher education (16). Glinkowski, Pawlowska and Kozlowska have surveyed the perception and knowledge of tele-health and tele-nursing among university students of nursing in Poland (17).In addition, the study of Butali et al. was on the use of IT among dental students and resident physicians (18). In a case in 2015, Baraka et al. assessed the acceptance and knowledge of IT in health care practice (19), while Sinha and Shetty studied the attitude of physicians towards the efficiency of HIT in Ayurveda educational hospital (20). Another study was done by Buabbas et al. in 2016 entitled "Health Sciences Students' Self-Assessment of Information and Communication Technology Skills and Attitude Toward e-Learning" (21). Manganello et al. also assessed the relation of health knowledge and using IT (22). Moreover, Shih fulfilled a study about attitude and perception of nurses towards HIT and their effects on the practice (2).

\section{Material and Methods}

This case study was conducted on both medical students who had passed at least two academic semesters and also on health care professionals with various academic levels, working in 65 referral educational hospitals in Iran in 2017. The subjects included 539 hospital staff assigned into three subgroups of medical doctors $(n=128)$, medical students $(n=97)$, and health record staff $(n=314)$. The Institutional Ethics Committee approved the study protocols. After describing the practical details of the project to participants, informed consent was obtained from all of them. To assess the subject's knowledge and practice of IT, a pretested self-administered questionnaire was given to subjects including three sections of "baseline general characteristics", "knowledge categories", and "attitude and practice". The sections of information knowledge, and attitude and practice information consisted of 19 and 16 questions respectively which were scaled as good, fair, and poor. To attain knowledge level towards IT, the score of more than $80 \%$ was scaled as good knowledge, between $60 \%$ and $79 \%$ was scaled as fair knowledge, and less than $60 \%$ was scaled as poor knowledge. Also, for determining attitude and practice state, the level of more than $60 \%$ was scaled as good knowledge, between 50\% and 59\% was scaled as fair knowledge, and less than 50\% was scaled as poor knowledge. The reliability of the questionnaire was determined by researchers through achieving an acceptable reliability of Cronbach's alpha (0.83). Moreover, the content validity was determined by a nominal group of five experts using professional judgment by obtaining a validity level of 0.85 . For statistical analysis, the results were presented as mean \pm standard deviation (SD). Categorical variables were compared using Chi-square test, and continuous variables were compared using T-test. The statistical software IBM(C) SPSSC Statistics version 21 
(IBMC Corp., Armonk, NY, USA) was used for the statistical analysis. Furthermore, P values of 0.05 or less were considered statistically significant.

\section{Results}

The response rate to the questions was $87.8 \%$ (539 out of 614) including 128 physicians, 97 students, and 314 staff. The overall age of subjects ranged from 25 to 57 years among which, 297 were male and 242 were female. The average ages of physicians, students, and staff were respectively $37.11 \pm 4.34$ years, $24.70 \pm 2.46$ years, and $33.21 \pm 4.34$ years with a significant difference among them $(\mathrm{p}=0.014)$. Regarding gender distribution, the frequency of male gender was $80.4 \%, 56.0 \%$, and $32.9 \%$ respectively with a significant difference $(p<0.001)$. Also, $87.8 \%$ of physicians, $26.0 \%$ of students, and $64.7 \%$ of staff were married $(\mathrm{p}<0.001)$. Considering the experience of computer training, 52 physicians $(40.6 \%), 73$ students $(75.3 \%)$, and 195 staff $(62.1 \%)$ had history of passing different courses of computer training. Among respondents, $77.1 \%$ owned a computer. A total of $27.9 \%$ of responders had a good level of knowledge towards computer science, while a poor level of knowledge was revealed in $28.2 \%$. Also, $41.1 \%$ had good attitude and practice habits, whereas $24.8 \%$ exhibited poor attitude and practice. As shown in Table 1 , there was no significant difference in the level of knowledge towards IT between physicians, students, and staff; therefore, good knowledge was respectively found in $16.4 \%, 32.0 \%$, and $33.1 \%$ and poor knowledge was also observed in $45.3 \%, 25.8 \%$, and $37.6 \%$, respectively ( $\mathrm{p}=0.304)$. Regarding attitude and practice habits, $28.9 \%$ of physicians, $50.5 \%$ of students, and $40.8 \%$ of staff had good attitude and practice habits, while poor attitude and practice habits were revealed in $30.5 \%, 4.1 \%$, and $29.2 \%$, respectively $(\mathrm{p}=0.163)$. As illustrated in Figures 1 to 3 , overall, the level of knowledge was positively associated with the score of attitude and practice $(\mathrm{r}=0.847, \mathrm{p}<0.001)$, whereas the higher knowledge level was related to the higher score of attitude and practice. This direct association was also found in three subgroups of physicians $(r=0.815, \mathrm{p}<0.001)$, students $(\mathrm{r}=0.779, \mathrm{p}<0.001)$, and staff $(\mathrm{r}=0.878$, $\mathrm{p}<0.001)$.

Table 1. Knowledge, attitude and practice habits in physicians, students and health recorder staff

\begin{tabular}{|l|l|l|l|l|l|l|}
\hline Group & Total $(\mathrm{n}=539)$ & Physicians $(\mathrm{n}=128)$ & Students $(\mathrm{n}=97)$ & Staff $(\mathrm{n}=314)$ & $\mathrm{p}$-value \\
\hline \multirow{3}{*}{ Knowledge } & Good & $155(28.8)$ & $21(16.4)$ & $31(32.0)$ & $104(33.1)$ & 0.304 \\
\cline { 2 - 8 } & Fair & $181(33.6)$ & $49(38.3)$ & $41(42.3)$ & $92(29.3)$ \\
\cline { 2 - 8 } & Poor & $203(37.7)$ & $58(45.3)$ & $25(25.8)$ & $118(37.6)$ & \\
\hline \multirow{3}{*}{ Attitude and Practice } & Good & $217(40.3)$ & $37(28.9)$ & $49(50.5)$ & $128(40.8)$ & 0.163 \\
\cline { 2 - 8 } & Fair & $184(34.1)$ & $52(40.6)$ & $44(45.4)$ & $92(29.3)$ & $94(29.9)$ \\
\cline { 2 - 7 } & Poor & $138(25.6)$ & $49(30.5)$ & $4(4.1)$ & & \\
\hline
\end{tabular}

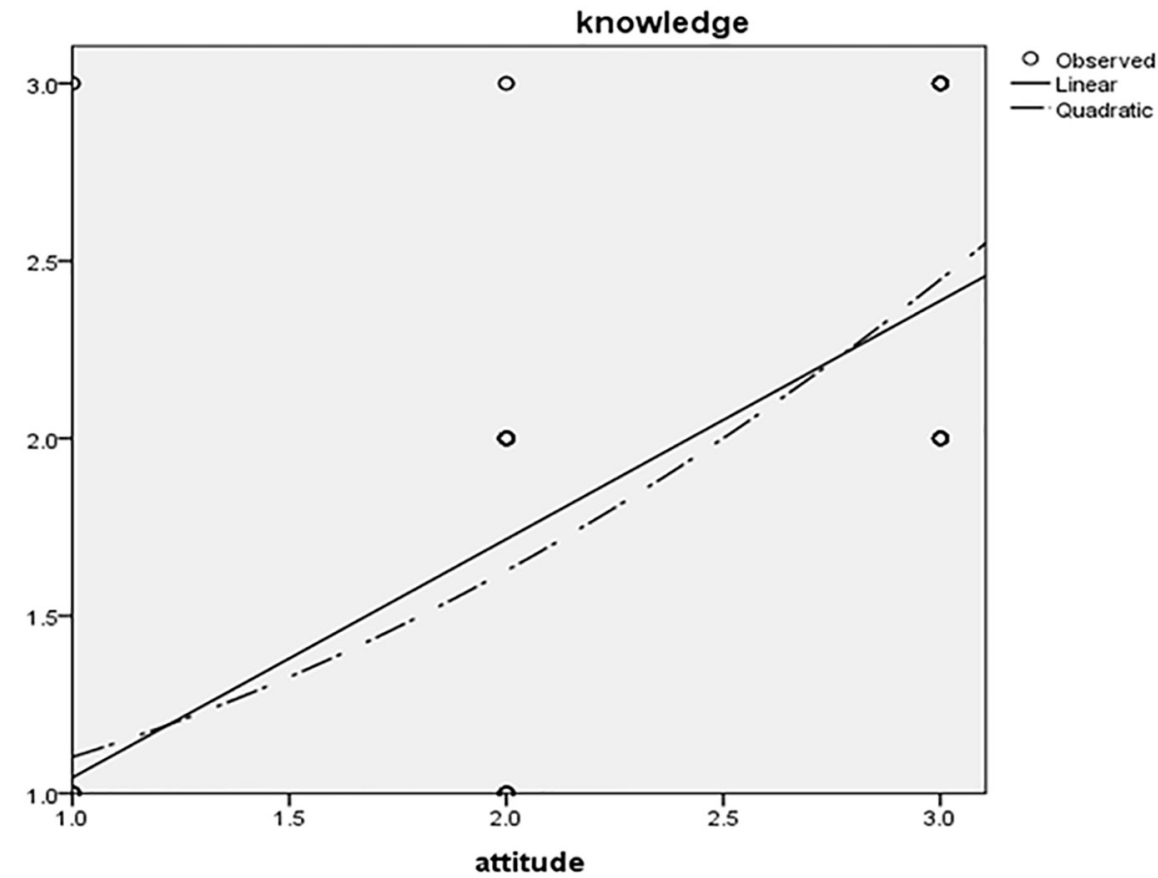

Figure 1. Association between knowledge and attitude in physicians 


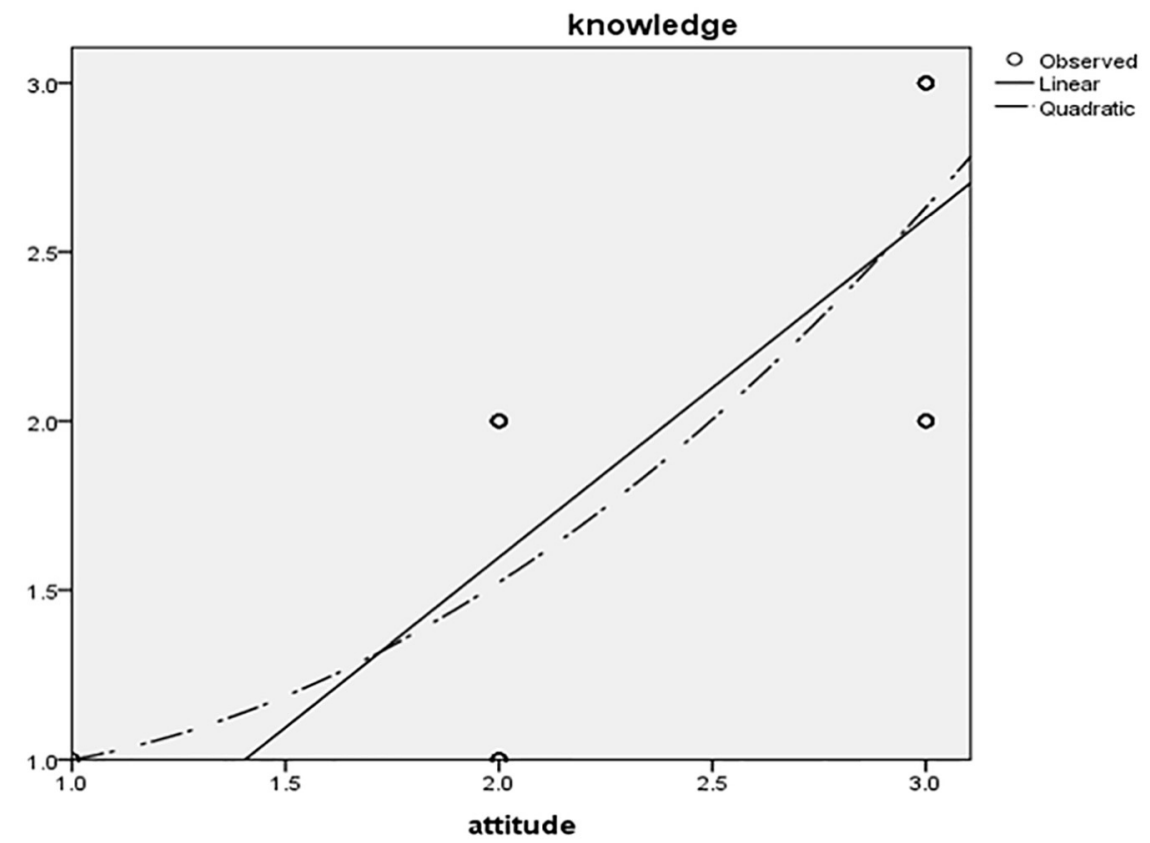

Figure 2. Association between knowledge and attitude in students

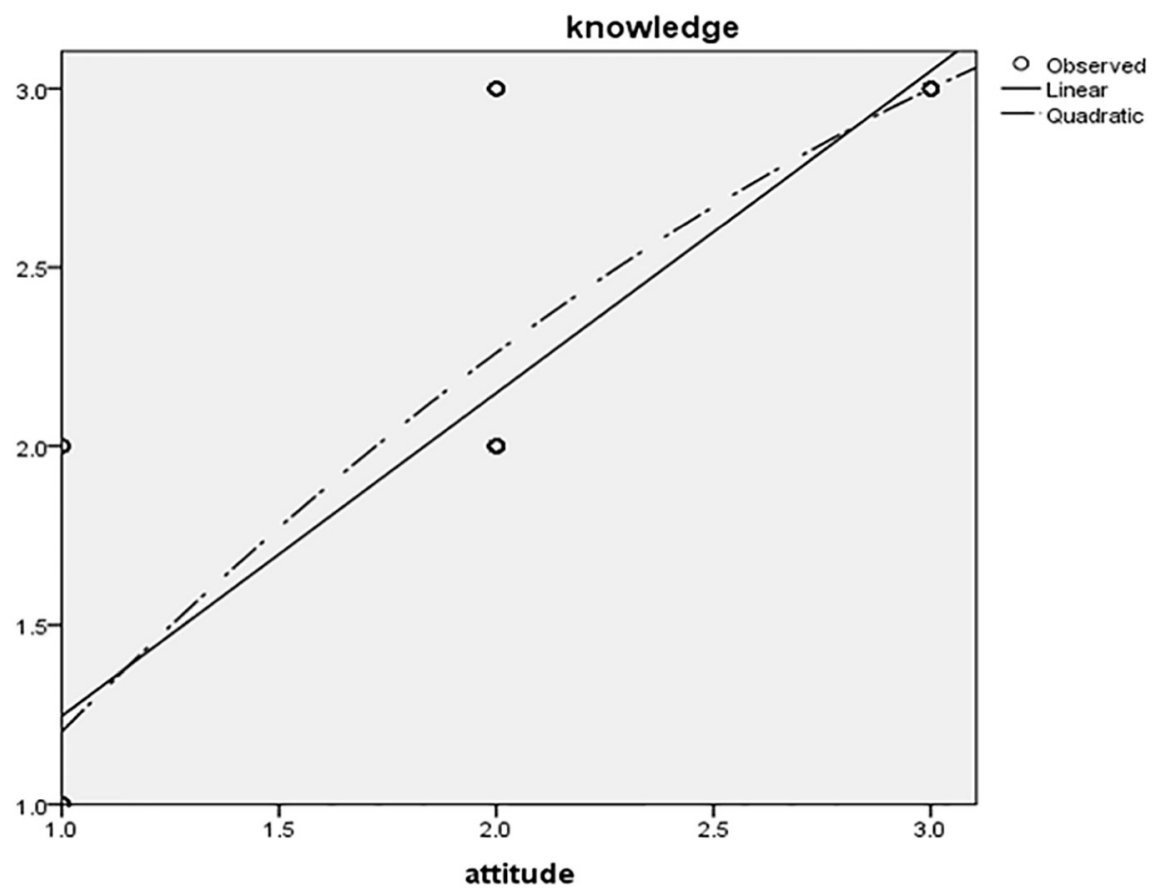

Figure 3. Association between knowledge and attitude in staff

\section{Discussion}

The present study had some significant points. First, the experience of passing computer courses was considerably different among the three subgroups of physicians, students, and staff, whereas it was more revealed in students followed by staff and physicians. It is probably due to more opportunities for students and staff to participate in computer courses, and also their situational needs required to learn computer skills in these two subgroups, whereas the students need to have this skill for educational and research requirements and the staff need to have computer skills due to the necessity of administrative activities such as data entry and management. On the whole, computer possession and practice among health care professionals and students were low. Despite the fact that most of the 
respondents owned a computer, only a small number of subjects in three subgroups had acceptable knowledge and practice habits. This is close to the findings of similar studies $(13,14)$. Bello et al. (13) found that only $18.9 \%$ of professionals and medical students had good computer knowledge while 58.8\% had average knowledge and 22.3\% showed poor knowledge. Mohammed et al. (14) discovered that only $33.7 \%$ of the health care workers had adequate computer knowledge. In a research carried out by Buabbas et al., the self-assessed results of students showed that initially, their level of HIT knowledge was low and only $9.29 \%$ of them have used computers professionally (21). In contrast to our findings, Gour and Srivastava (15) reported that $57.91 \%$ of health care professionals had knowledge about computers.. A study by Baraka et al. declared that $80.9 \%$ of participants had full or almost full training for using the Internet and IT applications. (19) Furthermore, Sinha \& Shetty who reviewed physicians' attitude towards HIT, concluded that the attitude of $75-80 \%$ of physicians in Ayurvedic Hospital was positive towards all kinds of health information technologies. (20) Glinkowski, Pawlowska and Kozlowska discovered that the definition of telemedicine was known by $82 \%$ of nursing students in Poland. However, in our study, $32.3 \%$ of medical students had good knowledge, while $50 \%$ showed good practice patterns which were in compliance with other findings $(13,14$, 18). In a study by Manganello et al., it was found that the use of HIT had a direct correlation with the level of health education, whereas the higher use of HIT was related to higher health education and the lower use of HIT was related to lower health education (22) Generally, the level of knowledge and attitude should be higher than the level obtained in our study.

\section{Conclusions}

Although the practice and knowledge about HIT among a number of physicians, students and staff in Iran was good, generally the rate of technology knowledge and practice seemed to be poor. This could be due to the lack of structured training and computer accessibility. Hence it is suggested that the university provide computer access for physicians, students and staff. Moreover, by reinforcing the educational infrastructures, the possibility of increasing knowledge of HIT among physicians, students and staff will be provided.

\section{Acknowledgments:}

A special word of thanks to all participants in this study.

\section{Conflict of Interest:}

There is no conflict of interest to be declared.

\section{Authors' contributions:}

All authors contributed to this project and article equally. All authors read and approved the final manuscript.

\section{References:}

1) Korhonen ES, Nordman T, Eriksson K. Technology and its ethics in nursing and caring journals: An integrative literature review. Nursing Ethics. 2015; 22(5): 561-76. doi: 10.1177/0969733014549881. PMID: 25335921.

2) Shih DR. Attitudes and Perceptions of Advanced Practice Nurses towards Health Information Technology and Its Effects on Caring. 2017.

3) Sittig DF. Electronic Health Records: Challenges in Design and Implementation. Apple Academic Press; 2014.

4) Ehrenfeld JM, Cannesson M. Monitoring technologies in acute care environments: a comprehensive guide to patient monitoring technology. New York: Springer; 2013.

5) DeSalvo KB. Federal health IT strategic plan 2015-2020. In: Services USDoHaH.The Office of the National Coordinator for Health Information Technology (ONC). 2014.

6) Amatayakul MK. Electronic health records. In: Sayles NB. Health information management technology: an applied approach. 4th ed. Chicago: American Health Information Management Association; 2013: 9471020.

7) Federal health IT strategic plan 2015-2020. Office of the National Coordinator for Health Information Technology (ONC) 2014.

8) Ahlan AR, Ahmad BI. User Acceptance of Health Information Technology (HIT) in Developing Countries: A Conceptual Model. Procedia Technology. 2014; 16: 1287-96. doi: 10.1016/j.protcy.2014.10.145.

9) Kijsanayotin B, Pannarunothai S, Speedie SM. Factors influencing health information technology adoption in Thailand's community health centers: Applying the UTAUT model. Int J Med Inform. 2009; 78(6): 40416. doi: 10.1016/j.ijmedinf.2008.12.005. PMID: 19196548. 
10) Weeger A, Gewald H. Acceptance and use of electronic medical records: An exploratory study of hospital physicians' salient beliefs about HIT systems. Health Systems. 2015; 4(1): 64-81. doi: 10.1057/hs.2014.11.

11) Yaghoubi J, Malek Mohammadi I, Iravani H, Attaran M, Gheidi A. Virtual Students' Perceptions of eLearning in Iran. Online Submission. 2008; 7(3).

12) Jahangard N. The Goals of Educations in the information Era. TAKFA Magazine. 2003; 1(5-6).

13) Bello IS, Arogundade FA, Sanusi AA, Ezeoma IT, Abioye-Kuteyi EA, Akinsola A. Knowledge and utilization of Information Technology among health care professionals and students in Ile-Ife, Nigeria: a case study of a university teaching hospital. J Med Internet Res. 2004; 6(4): e45. doi: 10.2196/jmir.6.4.e45. PMID: 15631969, PMCID: PMC1550621.

14) Mohammed E, Andargie G, Meseret S, Girma E. Knowledge and utilization of computer among health workers in Addis Ababa hospitals, Ethiopia: computer literacy in the health sector. BMC research notes. 2013; 6(1): 106. doi: 10.1186/1756-0500-6-106. PMID: 23514191, PMCID: PMC3610130.

15) Gour N, Srivastava D. Knowledge of computer among healthcare professionals of India: a key toward ehealth. Telemedicine and e-Health. 2010; 16(9): 957-62. doi: 10.1089/tmj.2010.0049. PMID: 21091287.

16) Srivastava TK, Waghmare LS, Jagzape AT, Rawekar AT, Quazi NZ, Mishra VP. Role of information communication technology in higher education: Learners perspective in rural medical schools. J Clin Diagn Res. 2014; 8(6): XC01-06. doi: 10.7860/JCDR/2014/8371.4448. PMID: 25121049, PMCID: PMC4129270.

17) Glinkowski W, Pawłowska K, Kozłowska L. Telehealth and telenursing perception and knowledge among university students of nursing in Poland. Telemed J E Health. 2013; 19(7): 523-9. doi: 10.1089/tmj.2012.0217. PMID: 23650941, PMCID: PMC3700067.

18) Butali A, Adeyemo W, Akinshipo A, Fashina A, Savage K. Use of information and communication technology among dental students and registrars at the faculty of dental sciences, University of Lagos. Nigerian journal of clinical practice. 2011; 14(4): 467-72. doi: 10.4103/1119-3077.91758. PMID: 22248952.

19) Barakah DM, Al Hasan MS, Alwakeel SS. Information Technology Adoption and Literacy in Health Care Practice: A Case Study. Journal of Advances in Information Technology. 2015; 6(1). doi: 10.12720/jait.6.1.49-53.

20) Sinha RK, Shetty SR. Attitude of Ayurveda doctors toward the impact of health information technology. J Ayurveda Integr Med. 2015; 6(2): 89. doi: 10.4103/0975-9476.146559. PMID: 26166998, PMCID: PMC4484054.

21) Buabbas AJ, Al-Shawaf HMH, Almajran AA. Health Sciences Students' Self-Assessment of Information and Communication Technology Skills and Attitude Toward e-Learning. JMIR Med Educ. 2016; $2(1)$ : e9.

22) Manganello J, Gerstner G, Pergolino K, Graham Y, Falisi A, Strogatz D. The relationship of health literacy with use of digital technology for health information: implications for public health practice. J Public Health Manag Pract. 2017; 23(4): 380-7. doi: 10.1097/PHH.0000000000000366. PMID: 26672402. 